\title{
Number needed to treat for interleukin inhibitors approved for the treatment of moderate-to-severe plaque psoriasis in Italy
}

\author{
Roberto Ravasio ${ }^{1}$, Antonio Costanzo ${ }^{2,3}$, Silvia Antonelli ${ }^{4}$, Alessia Maiorino ${ }^{4}$, Serena Losi ${ }^{4}$ \\ ${ }^{1}$ Health Publishing \& Services Srl, Milan - Italy \\ ${ }^{2}$ Dermatology, Department of Biomedical Sciences, Humanitas University, Pieve Emanuele, Milan - Italy \\ ${ }^{3}$ Dermatology, IRCCS Humanitas Research Hospital, Rozzano, Milan - Italy \\ ${ }^{4}$ Eli Lilly Italia S.p.A., Sesto Fiorentino - Italy
}

\begin{abstract}
Background: Interleukin (IL) inhibitors achieve greater levels of efficacy than older systemic therapies. We calculated the number needed to treat (NNT) of ixekizumab compared with other IL inhibitors approved in Italy for the treatment of moderate-to-severe plaque psoriasis.

Methods: The clinical efficacy was evaluated in terms of NNT, based on the results of a recent network metaanalysis (NMA) by the Cochrane Database of Systematic Reviews. The NMA investigated many systemic and biological treatments, but this analysis compared only the efficacy of the following IL inhibitors - brodalumab, guselkumab, ixekizumab, risankizumab, secukinumab, tildrakizumab and ustekinumab - for patients with moderate-to-severe plaque psoriasis. Drugs were compared and ranked according to effectiveness considering the PASI (Psoriasis Area and Severity Index) 90 score.

Results: One-hundred and forty trials (51,749 patients) were included in the NMA. Considering the proportion of patients who achieve PASI90, ixekizumab showed the lowest NNT among all comparators (ixekizumab 2.01 [2.46-3.00]; risankizumab 2.05 [2.50-3-05]; guselkumab 2.16 [2.68-3.36]; secukinumab 2.40 [2.90-3.51]; brodalumab 2.61 [3.18-3.88]; ustekinumab 3.44 [4.12-4.95]; tildrakizumab 3.10 [4.15-5.59].

Conclusion: The findings show that ixekizumab is the most effective option (NNT) for the treatment of moderateto-severe plaque psoriasis.

Keywords: Interleukin inhibitor, Ixekizumab, Number needed to treat, Plaque psoriasis
\end{abstract}

\section{Introduction}

Psoriasis is a chronic immune-mediated inflammatory disease that comprises a wide spectrum of dermatological manifestations depending on clinical features and severity of the disease $(1,2)$. Even if the etiology of psoriasis is not fully understood, there is a connection between environmental factors and genetic susceptibility (3). In fact, some environmental factors, such as stress and infections, can trigger or exacerbate the disease $(4,5)$.

Received: December 22, 2020

Accepted: March 22, 2021

Published online: April 15, 2021

\section{Corresponding author:}

Roberto Ravasio

Health Publishing \& Services Srl

Piazza Duca d'Aosta 12

20124, Milan - Italy

rravasio@aboutpharma.com
The typical cutaneous manifestations and chronic course of psoriasis have a significant impact on patients' quality of life as psoriasis is associated with potentially invalidating psychological and social consequences (6). Moreover, in patients with severe disease there is a higher mortality risk compared to the general population (hazard ratio [HR] 1.5; 95\% confidence interval [CI] 1.3-1.7) (7,8).

With a prevalence of $2.9-3.1 \%(7,9)$ and an incidence of 230-310 new cases per 100,000 persons/year (10), psoriasis is one of the most common dermatological diseases with about 1.5-2.5 million patients in Italy. The diagnosis of psoriasis is usually clinical and based mainly on the physical examination and the patient's medical history; skin biopsy is rarely needed to confirm the diagnosis (11).

There are several forms of psoriasis, although plaque psoriasis (PP) is the most common (about $80 \%$ of patients) (11-13). PP is characterized by the presence of erythematousdesquamative lesions with clear margins, mainly located on the limbs (knees and elbows), lumbosacral region and scalp $(11,12)$, often accompanied by symptoms such as itching and pain $(13,14)$. About $20 \%$ of patients develop moderateto-severe PP $(15,16)$. 
Different outcome measures are used to evaluate the severity of PP and the efficacy of treatment; the Psoriasis Area and Severity Index (PASI) is one of the most frequently used (16-18). PASI combines a quantitative (proportion of affected area for each body region) and a qualitative (presence of erythema, scaling and skin thickening) skin disease assessment.

The PASI score is measured on a scale from 0 (absence of disease) to a maximum of 72 and response to treatment is often measured in terms of percentage decrease in the PASI score, with values of 75\% (PASI75), 90\% (PASI90) and 100\% (PASI100) usually reported in clinical trials $(15,16)$. A PASI score $>10$ generally indicates moderate disease $(15,16)$.

At present, there is no cure for PP, while several treatments can, however, provide control of symptoms of the disease.

Compared to the administration of traditional systemic therapies, the availability of new biological agents (antitumor necrosis factor [TNF]- $\alpha$ and interleukin [IL] inhibitors) has profoundly changed the management of moderate-tosevere PP (19). In particular, the use of IL inhibitors such as ustekinumab (IL-12/23), secukinumab (IL-17), ixekizumab (IL-17), brodalumab (IL-17), guselkumab (IL-23), tildrakizumab (IL-23) and risankizumab (IL-23) allows a substantial proportion of patients to achieve significant levels of skin clearance (19).

\section{Objectives}

The present analysis was carried out to estimate the number needed to treat (NNT) of the IL inhibitors currently reimbursed in Italy for the treatment of moderate-to-severe PP: brodalumab, guselkumab, ixekizumab, risankizumab, secukinumab, tildrakizumab and ustekinumab.

\section{Methods}

\section{Network meta-analysis}

This analysis is based on the results of a recent network meta-analysis (NMA) by the Cochrane Database of Systematic Reviews (19). NMA is a technique that synthesizes direct and indirect comparisons of interventions (i.e. drugs). The Cochrane NMA compared efficacy and safety of the principal drugs (conventional systemic therapies, small molecules, anti-TNF- $\alpha$, IL inhibitors) used for the treatment of moderateto-severe PP (19). Drugs were compared and ranked according to effectiveness considering the PASI90 score $(20,21)$.

The NMA considered a total of 140 randomized controlled trials (RCTs), involving 51,749 patients (overall average age: 45 years; male: 67\%). Eighty-two trials compared systemic treatments with placebo, 41 trials compared systemic treatments with systemic treatments and 17 trials compared systemic treatments with systemic treatments and placebo. Most RCTs were short term and the PASI90 scores presented in the NMA were measured from 8 to 24 weeks after patients were randomized (induction phase). In terms of reaching PASI90, anti-IL-17 (ixekizumab, secukinumab and brodalumab), anti-IL-12/23 (ustekinumab), anti-IL-23 (risankizumab, guselkumab and tildrakizumab) and anti-TNF- $\alpha$ were significantly more effective than small molecules and conventional systemic therapies (19). At drug level, ixekizumab, secukinumab, brodalumab, risankizumab and guselkumab were significantly more effective (PASI90) than ustekinumab, adalimumab, certolizumab and etanercept (19). For the risk of serious side effects, there were no significant differences between any of the systemic treatments compared with placebo (19).

Table I lists the IL inhibitors that are currently reimbursed by the Italian National Health Service (iNHS) with their relative efficacy (PASI90) compared to placebo (19). The NMA results showed that ixekizumab was more effective than other ILs in treating moderate-to-severe PP when assessed using an outcome that required 90\% improvement (PASI90).

\section{Number needed to treat}

The concept of NNT was presented by Laupacis et al in 1988 (22). The NNT is an absolute effect measure which represents the number of patients to be treated to obtain a therapeutic benefit (responders) (22-24). The NNT corresponds to the reciprocal of the absolute risk reduction (ARR), where the ARR corresponds to the difference in the incidence of the event between the experimental (experimental event rate, EER) and control groups (control event rate, CER) (22-24), as shown in Equation [1]. In the present analysis the NNT was calculated considering the efficacy (PASI90) compared to placebo for the IL inhibitors reimbursed in Italy for the treatment of moderate-to-severe PP. In general, the NNT is the number of patients that need to be treated with one of the IL inhibitors (experimental group) compared to placebo (control group) to

TABLE I - Network meta-analysis: PASI90 induction phase results (19)

\begin{tabular}{|c|c|c|c|}
\hline \multirow[t]{2}{*}{ Drug } & \multirow{2}{*}{$\begin{array}{c}\text { No of } \\
\text { participants } \\
\text { (studies) }\end{array}$} & \multicolumn{2}{|c|}{ PASI90* } \\
\hline & & $\begin{array}{c}\text { Treatment } \\
(95 \% \mathrm{Cl})\end{array}$ & Placebo \\
\hline Brodalumab & $\begin{array}{c}\text { 4,109 } \\
\text { (5 RCTs) }\end{array}$ & $\begin{array}{c}32.9 \% \\
(27.3 \%-39.8 \%)\end{array}$ & $1.5 \%$ \\
\hline Guselkumab & $\begin{array}{c}1,767 \\
\text { (5 RCTs) }\end{array}$ & $\begin{array}{c}38.8 \% \\
(31.3 \%-47.9 \%)\end{array}$ & $1.5 \%$ \\
\hline Ixekizumab & $\begin{array}{c}3,268 \\
\text { (4 RCTs) }\end{array}$ & $\begin{array}{c}42.2 \% \\
(34.8 \%-51.2 \%)\end{array}$ & $1.5 \%$ \\
\hline Risankizumab & $\begin{array}{c}1,476 \\
\text { (4 RCTs) }\end{array}$ & $\begin{array}{c}41.5 \% \\
(34.3 \%-50.2 \%)\end{array}$ & $1.5 \%$ \\
\hline Secukinumab & $\begin{array}{c}2,895 \\
\text { (8 RCTs) }\end{array}$ & $\begin{array}{c}36.0 \% \\
(30.0 \%-43.1 \%)\end{array}$ & $1.5 \%$ \\
\hline Tildrakizumab & $\begin{array}{c}1,903 \\
\text { (3 RCTs) }\end{array}$ & $\begin{array}{c}25.6 \% \\
(19.4 \%-33.8 \%)\end{array}$ & $1.5 \%$ \\
\hline Ustekinumab & $\begin{array}{c}4,231 \\
\text { (9 RCTs) }\end{array}$ & $\begin{array}{c}25.8 \% \\
(21.7 \%-30.6 \%)\end{array}$ & $1.5 \%$ \\
\hline
\end{tabular}

$\mathrm{Cl}=$ confidence interval; PASI = Psoriasis Area and Severity Index; RCT = randomized controlled trial.

*PASI90 scores presented in the NMA were measured from 8 to 24 weeks after patients were randomized (induction phase). 
obtain a therapeutic benefit (achieve PASI90). It is useful to remember that the lower the NNT, the higher the effectiveness of the intervention versus the selected comparators.

$$
\mathrm{NNT}=\frac{1}{\mathrm{ARR}}=\frac{1}{(\mathrm{ERR}-\mathrm{CRR})}=\frac{1}{\left(P A S / 90_{L}-P A S / 90_{P}\right)}
$$

where IL = IL inhibitor; $\mathrm{P}=$ placebo.

\section{Sensitivity analysis}

A sensitivity analysis was performed with the aim of evaluating the degree of uncertainty of the basecase NNT results (25). As the efficacy data (PASI90) estimated by the NMA (19) was used to calculate the NNT values, the uncertainty of the basecase NNT values was tested in a one-way sensitivity analysis (OWSA) according to the confidence interval efficacy data (PASI90) of each IL reported in the NMA (Tab. I). This analysis was performed to determine the impact of the efficacy data variation of the NNT values estimated in the base case.

\section{Results}

\section{Number needed to treat}

Referring to the PASI90 score, Figure 1 shows the NNT of the seven IL inhibitors in the induction phase of treatment. Considering the proportion of patients who achieve PASI90, ixekizumab always had the lowest NNT among all comparators.

\section{Sensitivity analysis}

Figure 1 details the results of the sensitivity analysis where the efficacy data (PASI90) are reported in the NMA
(19) range according to the confidence intervals (Tab. I). In all comparisons (upper and lower bounds), ixekizumab remained the therapeutic alternative with the lowest NNT values.

\section{Discussion}

The Consolidated Standards of Reporting Trials (CONSORT) recommends the use of relative (i.e. relative risk) and absolute (i.e. NNT) measures of effect for RCTs $(25,26)$. Likewise, the British Medical Journal (BMJ) also requests to report relative and absolute risks in RCTs (23). However, the RCT results are not commonly reported in terms of NNT, while relative measures, such as relative risk or odds ratio, are more extensively used in scientific publications (27-30). Together with all the other measures of effects, the NNT should be a valuable supportive tool to assist physicians in selecting treatments in daily clinical practice $(31,32)$. Furthermore, the NNT should be used in benefit-risk assessments, thereby supporting health decision makers (33-35).

This study evaluated the NNT for the induction phase of seven IL inhibitors currently reimbursed by the iNHS for the treatment of moderate-to-severe PP. Ixekizumab was associated with the lowest NNT compared to all other IL inhibitors. Our comparison is derived from the results of a Cochrane NMA (19) that highlighted the greater efficacy (PASI90) of ixekizumab compared to brodalumab, guselkumab, risankizumab, secukinumab, tildrakizumab and ustekinumab in the treatment of moderate-to-severe PP. NMA, as indirect comparison, provides observational evidence, since the treatments being compared have not been randomized across studies. Compared to previous review, the Cochrane NMA included more treatment, more trials $(n=140)$ and more patients ( $n=51,749)$. In the Cochrane NMA there is no evidence of heterogeneity either in direct comparisons or in the entire networks and there is no evidence that relevant

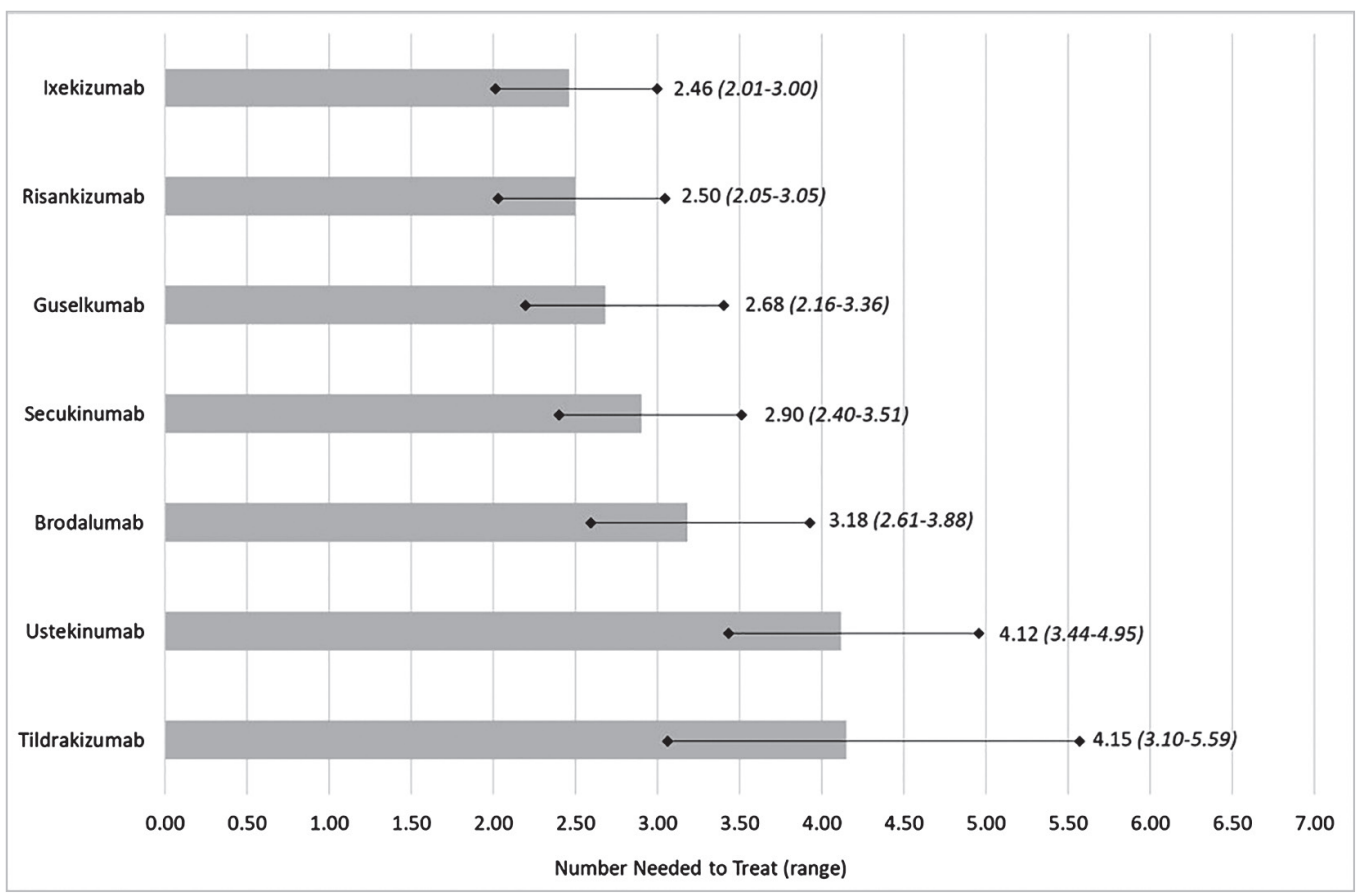

Fig. 1 - NNT in the induction phase of treatment.*

*PASI9O scores presented in the NMA were measured from 8 to 24 weeks after patients were randomized (induction phase). 
variables such as age, sex, duration or severity of PP varied across comparison. We cannot assume that the clinical results are perfectly generalizable to the Italian context, but, anyway, we believe that the NMA is a valid statistical approach to generate comparative efficacy data (anti-IL vs placebo) when head-to-head comparisons are not available for all or the most of the treatments evaluated $(36,37)$. Nevertheless, the lack of head-to-head comparisons could be a limitation of this analysis. To justify this lack of data, a sensitivity analysis on NMA PASI90 was conducted. The results of the sensitivity analysis confirmed the base case scenario.

Based on the results of another NMA (38), a Spanish study evaluated the NNT of ixekizumab, secukinumab, ustekinumab, adalimumab, etanercept and infliximab for moderateto-severe PP (39). This NMA provided indirect comparisons (PASI75, PASI90 and PASI100) for all biologic drugs administered in the treatment of moderate-to-severe PP. Consistent with our finding, ixekizumab showed the lowest NNT for all PASI response scores.

\section{Conclusions}

Based on NMA's efficacy data (PASI90), ixekizumab showed the lowest NNT value for the treatment of moderate-to-severe PP compared to brodalumab, guselkumab, risankizumab, secukinumab, tildrakizumab and ustekinumab. The NNT allows to rank alternative treatments based on their efficacy, supporting clinicians, payers and other healthcare stakeholders on drug choice.

\section{Authors' contributions}

RR designed the study and drafted the manuscript. AC, SA, AM and $S L$ reviewed the manuscript. All authors read and approved the final version of the manuscript.

\section{Disclosures}

Conflicts of interest: The agreement signed by Health Publishing \& Services and Eli Lilly Italia S.p.A. does not create any entityship, joint venture or any similar relationship between parties. Health Publishing \& Services is an independent company. Neither Health Publishing \& Services nor any of their representatives are employees of Eli Lilly Italia S.p.A. for any purpose. RR is a consultant of Health Publishing \& Services. AC has received honoraria as advisor or speaker from Abbvie, Janssen, Pfizer, Boehringer, Eli Lilly, Celgene, UCB, Galderma and Novartis. SA, AM and SL are full-time employees of Eli Lilly Italia S.p.A.

Financial support: This research was made possible by an educational grant from Eli Lilly Italia S.p.A.

\section{References}

1. Sarac G, Koca TT, Baglan T. A brief summary of clinical types of psoriasis. North Clin Istanb. 2016;3(1):79-82. PubMed

2. World Health Organization. Psoriasis: Report by the Secretariat. 2013; Online Accessed January 13, 2016.

3. Elder JT, Bruce AT, Gudjonsson JE, et al. Molecular dissection of psoriasis: integrating genetics and biology. J Invest Dermatol. 2010;130(5):1213-1226. CrossRef PubMed

4. Jariwala SP. The role of dendritic cells in the immunopathogenesis of psoriasis. Arch Dermatol Res. 2007;299(8):359-366. CrossRef PubMed
5. Lowes MA, Kikuchi T, Fuentes-Duculan J, et al. Psoriasis vulgaris lesions contain discrete populations of Th1 and Th17 T cells. J Invest Dermatol. 2008;128(5):1207-1211. CrossRef PubMed

6. Kurd SK, Troxel AB, Crits-Christoph P, Gelfand JM. The risk of depression, anxiety, and suicidality in patients with psoriasis: a population-based cohort study. Arch Dermatol. 2010;146(8): 891-895. PubMed

7. Saraceno R, Mannheimer R, Chimenti S. Regional distribution of psoriasis in Italy. J Eur Acad Dermatol Venereol. 2008;22(3):324-329. CrossRef PubMed

8. Gelfand JM, Troxel AB, Lewis JD, et al. The risk of mortality in patients with psoriasis: results from a population-based study. Arch Dermatol. 2007;143(12):1493-1499. CrossRef PubMed

9. Naldi L, Colombo P, Placchesi EB, et al. Study design and preliminary results from the pilot phase of the PraKtis study: selfreported diagnoses of selected skin diseases in a representative sample of the Italian population. Dermatology. 2004;208: 38-42. CrossRef PubMed

10. Vena GA, Altomare G, Ayala F, et al. Incidence of psoriasis and association with comorbidities in Italy: a 5-year observational study from a national primary care database. Eur J Dermatol. 2010;20(5):593-598. PubMed

11. Boehncke WH, Schön MP. Psoriasis. Lancet. 2015;386(9997): 983-994. CrossRef PubMed

12. Di Meglio P, Villanova F, Nestle FO. Psoriasis. Cold Spring Harb Perspect Med. 2014;4(8):a015354. CrossRef PubMed

13. Menter A, Gottlieb A, Feldman SR, et al. Guidelines of care for the management of psoriasis and psoriatic arthritis: Section 1. Overview of psoriasis and guidelines of care for the treatment of psoriasis with biologics. J Am Acad Dermatol. 2008;58(5): 826-850. CrossRef PubMed

14. Icen M, Crowson CS, McEvoy MT, Dann FJ, Gabriel SE, Maradit Kremers $\mathrm{H}$. Trends in incidence of adult-onset psoriasis over three decades: a population-based study. J Am Acad Dermatol. 2009;60(3):394-401. CrossRef PubMed

15. Pathirana D, Ormerod AD, Saiag P, et al. European S3-guidelines on the systemic treatment of psoriasis vulgaris. J Eur Acad Dermatol Venereol. 2009;23(suppl 2):1-70. CrossRef PubMed

16. Gisondi P, Altomare G, Ayala F, et al. Italian guidelines on the systemic treatments of moderate-to-severe plaque psoriasis. J Eur Acad Dermatol Venereol. 2017;31(5):774-790. CrossRef PubMed

17. Naldi L. Scoring and monitoring the severity of psoriasis. What is the preferred method? What is the ideal method? Is PASI passé? facts and controversies. Clin Dermatol. 2010;28(1): 67-72. CrossRef PubMed

18. Spuls PI, Lecluse LL, Poulsen ML, Bos JD, Stern RS, Nijsten T. How good are clinical severity and outcome measures for psoriasis?: quantitative evaluation in a systematic review. J Invest Dermatol. 2010;130(4):933-943. CrossRef PubMed

19. Sbidian E, Chaimani A, Afach S, et al. Systemic pharmacological treatments for chronic plaque psoriasis: a network metaanalysis. Cochrane Database Syst Rev. 2020;1(1):CD011535. CrossRef PubMed

20. Puig L. PASI90 response: the new standard in therapeutic efficacy for psoriasis. J Eur Acad Dermatol Venereol. 2015;29(4): 645-648. CrossRef PubMed

21. Strober B, Papp KA, Lebwohl M, et al. Clinical meaningfulness of complete skin clearance in psoriasis. J Am Acad Dermatol. 2016;75(1):77-82.e7. CrossRef PubMed

22. Laupacis A, Sackett DL, Roberts RS. An assessment of clinically useful measures of the consequences of treatment. N Engl J Med. 1988;318(26):1728-1733. CrossRef PubMed

23. Mendes D, Alves C, Batel-Marques F. Number needed to treat (NNT) in clinical literature: an appraisal. BMC Med. 2017;15(1):112. CrossRef PubMed 
24. Cook RJ, Sackett DL. The number needed to treat: a clinically useful measure of treatment effect. BMJ. 1995;310(6977): 452-454. CrossRef PubMed

25. Altman DG, Schulz KF, Moher D, et al; CONSORT GROUP (Consolidated Standards of Reporting Trials). The revised CONSORT statement for reporting randomized trials: explanation and elaboration. Ann Intern Med. 2001;134(8):663-694. CrossRef PubMed

26. Moher D, Hopewell S, Schulz KF, et al. CONSORT 2010 explanation and elaboration: updated guidelines for reporting parallel group randomised trials. BMJ. 2010;340(Mar23 1):c869. CrossRef PubMed

27. Hildebrandt $M$, Vervölgyi $E$, Bender R. Calculation of NNTs in RCTs with time-to-event outcomes: a literature review. BMC Med Res Methodol. 2009;9(1):21. CrossRef PubMed

28. Nuovo J, Melnikow J, Chang D. Reporting number needed to treat and absolute risk reduction in randomized controlled trials. JAMA. 2002;287(21):2813-2814. CrossRef PubMed

29. Alonso-Coello P, Carrasco-Labra A, Brignardello-Petersen R, et al. Systematic reviews experience major limitations in reporting absolute effects. J Clin Epidemiol. 2016;72:16-26. CrossRef PubMed

30. Citrome L. Relative vs. absolute measures of benefit and risk: what's the difference? Acta Psychiatr Scand. 2010;121(2): 94-102. CrossRef PubMed

31. Straus SE, Glasziou P, Richardson WS, Haynes RB. Evidencebased medicine: how to practice and teach it. London: Churchill Livingstone; 2011.

32. Citrome L, Ketter TA. When does a difference make a difference? Interpretation of number needed to treat, number needed to harm, and likelihood to be helped or harmed. Int J Clin Pract. 2013;67(5):407-411. CrossRef PubMed

33. Mt-Isa S, Hallgreen CE, Wang N, et al; IMI-PROTECT benefit-risk participants. Balancing benefit and risk of medicines: a systematic review and classification of available methodologies. Pharmacoepidemiol Drug Saf. 2014;23(7):667-678. CrossRef PubMed

34. Mendes D, Alves C, Batel-Marques F. Number needed to harm in the post-marketing safety evaluation: results for rosiglitazone and pioglitazone. Pharmacoepidemiol Drug Saf. 2015;24(12):1259-1270. CrossRef PubMed

35. Mendes D, Alves C, Batel Marques F. Testing the usefulness of the number needed to treat to be harmed (NNTH) in benefitrisk evaluations: case study with medicines withdrawn from the European market due to safety reasons. Expert Opin Drug Saf. 2016;15(10):1301-1312. CrossRef PubMed

36. Greco T, Biondi-Zoccai G, Saleh O, et al. The attractiveness of network meta-analysis: a comprehensive systematic and narrative review. Heart Lung Vessel. 2015;7(2):133-142. PubMed

37. Greco T, Landoni G, Biondi-Zoccai G, D’Ascenzo F, Zangrillo A. A Bayesian network meta-analysis for binary outcome: how to do it. Stat Methods Med Res. 2016;25(5):1757-1773. CrossRef PubMed

38. Hartz SDY, Kiri SH, Schacht A, Walzer S, Dakin H. Network metaanalysis to evaluate the efficacy of ixekizumab in the treatment of moderate-to-severe psoriasis. (Poster). International Society for Pharmacoeconomics and Outcomes (ISPOR), 19th Annual European Congress; 2016.

39. Núñez M, Huete T, de la Cueva P, Sacristán JA, Hartz S, Dilla T. A cost-per-number needed to treat analysis assessing the efficiency of biologic drugs in moderate to severe plaque psoriasis. Actas Dermosifiliogr. 2019;110(7):546-553. CrossRef PubMed 